\title{
THE OSLO STUDY OF UNTREATED SYPHILIS * $†$ REVIEW AND COMMENTARY
}

\author{
BY \\ L. W. HARRISON \\ London
}

Some books are to be tasted, others to be swallowed, and some few to be chewed and digested, that is . . . some few to be read wholly, and with diligence and attention.

F. BACON

This is eminently a work which should be read wholly, and with diligence and attention by all venereologists, whether they are only readers or both readers and authors : readers, so that they may learn-if they have not done so already-to read critically, not confining themselves to "Conclusions"; and authors that they may be strengthened in avoiding the pitfalls of drawing large inferences from small data and of quoting with approval " Conclusions" which they have not satisfied themselves are justified by the evidence.

The material on which this work is based is unique and for its re-study not only venereologists but colleagues in other branches of medicine should be grateful to those mentioned below, and their assistants, who have brought it about.

Since the Editor of the British Journal of Venereal Diseases, realizing the importance of this work, has allotted enough space to permit of a review which is not merely a glorified account of its contents but a critical commentary, and since many readers of this Journal may not be acquainted with events in the syphilological world as far back as a quarter of a century ago, it seems appropriate to give here a short history of the events which led to the present study.

From 1891 to 1910, Caesar Boeck, Professor of Dermatology in the University of Oslo, practically forbade the use of mercury in the treatment of the syphilitic cases in his wards, believing that mercury generally interfered with the patient's own defence

\footnotetext{
* Invited review, received for publication April 10, 1956.

* Invited review, received for publication April 10, 1956. $\dagger$ "An Epidemiological Investigation of the Natural Course of
the Syphilitic Infection based upon a Re-study of the BoeckBruusgaard Material" by Trygve Gjestland (1955). Acta derm.venereol. (Stockh.), 35, Suppl. 34 ; pp. 368 with 83 Tables and 12 Figs, plus Appendix of 56 pp. with 30 Tables and 2 Figs.
}

mechanism, which he thought was better than the metal. In the period mentioned, approximately 2,000 cases of early syphilis were dealt with on these lines in his wards and a number of years later (1925-27) his successor, E. Bruusgaard, carried out an investigation to discover how Boeck's cases had fared. As a result, Bruusgaard (1929) published an article of which a free translation of the title is "The Fate of Syphilitics who have received no Specific Treatment".

His article excited a great deal of attention, even leaders in some medical periodicals, and here I may perhaps be pardoned for introducing a personal note. At that time I was reviewing articles for the Bulletin of Hygiene, and in due course I received a slip which was an invitation to review Bruusgaard's paper. I read the paper and returned the slip marked "Not worth review" because I thought the results recorded by Bruusgaard were not statistically sound and could be misleading; this was no reflection on Bruusgaard, who, for the most part, enjoined caution in the inferences to be drawn from his material. My rejection of the paper was a mistake as I soon discovered in the, to my mind, unwarranted inferences being drawn from Bruusgaard's data by different authors. About 2 years later a paper by a distinguished dermatologist, in which some quite illogical inferences were drawn from the Bruusgaard report, provided me with an excuse for reviewing the Bruusgaard paper together with that of the dermatologist. In my review (Harrison, 1932, 1939, 1941) I tried to show that, for purposes of prognosis of untreated syphilis, the Bruusgaard statistics were useless. My criticisms were repeated in various papers by myself and in correspondence with American and other colleagues - they are freely quoted in the study under present review-but the Bruusgaard percentages of ultimate results continued to be quoted in various articles 
and text-books, sometimes with and sometimes without acknowledgment. Then W. T. Sowder (1940) of the Johns Hopkins School of Medicine published in the American Journal of Syphilis a re-study of the Bruusgaard paper and showed that the material analysed by Bruusgaard was not a fair random sample but highly selected.

Perhaps from all this may have sprung the idea of re-examining as many of Boeck's cases as could be traced and the records of the remainder, and one can readily endorse the gratitude expressed by Trygve Gjestland, the author of the study under review, in his preface, to those who brought it about. These, mentioned in the author's order, are : Prof. N. Danbolt, Chief of the University Dermatological Clinic, Oslo ; Dr. T. Guthe, Chief of the Venereal Diseases and Treponematosis Division of WHO ; Dr. Joseph Earle Moore, Johns Hopkins Hospital, who, with Dr. J. R. Heller, at that time Chief of the Venereal Diseases Division of the United States Public Health Department, used his great influence in obtaining funds from the U.S.P.H. without which the re-study could not have been carried out ; Surg.-Gen. Karl Evang, Chief of the Norwegian Public Health Service ; and Dr. E. Gurney Clark, Professor of Epidemiology, University of Columbia, in whose department the new figures obtained from the Oslo records were analysed by the author. To Prof. Clark and his staff Gjestland makes special acknowledgment for constructive criticism and guidance, and he was helped by Dr. Fertig, Professor of Biostatistics, and Dr. Kingsley Davis, Director of the Bureau of Applied Social Research. Altogether this is an imposing list of collaborators which gives a clue to the many angles from which Gjestland examined the Boeck material.

In his Introduction the author gives a short history of Bruusgaard's Study - the details of Bruusgaard's findings are shown in six Tables in the Appendix to the present study-and criticizes the findings on grounds which need not be given here.

The author quotes Bruusgaard as having himself warned that the acceptance of his data should be made "with the reservations the nature of the material necessitates". He also quotes a number of extracts from books and articles by various syphilologists of repute who attached much more importance to the Bruusgaard figures than has the present reviewer. In this section Gjestland shows quite clearly that there were strong grounds for the re-examination of the Boeck-Bruusgaard material if this was to be of any value either academically or practically.
In his second chapter Gjestland discusses other investigations on the outcome of untreated syphilis, notably the Alabama group "left untreated for investigative purposes in comparing the effects on health and longevity of an untreated syphilitic population with one non-infected (Vonderlehr, Clark, Wenger, and Heller, 1936; Heller and Bruyere, 1946; Deibert and Bruyere, 1946 ; Pesare, Bauer, and Gleeson, 1950) ", and to this he adds the autopsy studies by Rosahn (1937). Throughout the work under review Gjestland frequently quotes the Alabama and the Rosahn figures for comparison with those obtained by himself from the Boeck cases.

In his third chapter he quotes the views of Caesar Boeck in defence of his practical non-use of mercury and discusses carefully, with the thoroughness which characterizes this study, the reasons for his having found only 1,978 cases in this basic material as contrasted with the 2,181 said to have been the basis of the Bruusgaard investigation.

For the purposes of the present re-study, 574 non-Norwegians and non-residents of Oslo were excluded, reducing the basic material to 1,404 cases; the author shows in great detail that this exclusion left the 1,404 cases fully representative of the original 1,978 .

The limitation of the re-study to residents (or potential residents) reduced the percentage of males from 36.5 in the original 1,978 , to 31.8 in the 1,404. The proportion of 1 male to $2 \cdot 1$ females in this material was the exact reverse of the sex ratio of the patients reported for syphilis to the Oslo City Health Department during the Boeck reign, the reason being that Boeck's female ward was twice the size of the male ward. The different manifestations observed in the original study group are related to the respective sexes and their ages on first admission to Boeck's wards. The occupational status and the districts in which the patients resided in Oslo are also noted, and from this it is clear that most of Boeck's cases were what are commonly called under-privileged and came from the slum district of Oslo. From a Table showing the distribution of the patients by sex and stage of syphilis on final diagnosis the percentages of the 446 males and the 958 females respectively appeared as follows :

Primary, 0.9 males and 0.3 females ;

Primary and secondary, 42.6 and 20.5 ;

Secondary, $52 \cdot 2$ and 73.6 ;

Clinical secondary relapse, $4 \cdot 3$ and $5 \cdot 6$.

Some pages later, Gjestland discusses the validity of these diagnoses made at a time when no help was 
available from the microscope or the test-tube. On the strength of the diagnostic acumen of Boeck and his staff and the fact of the patients being under observation for an average of several weeks, he sees no reason to doubt the original diagnoses. Personally, as one of those who questioned the validity of the original diagnoses when the Bruusgaard report was under discussion, as one who has seen the very elect mistaken when reliance had perforce to be placed only on clinical signs and has seen syphilis imitated by various skin diseases, I retain some scepticism but do not think mistakes in diagnosis made any very material difference to the results recorded in the present study.

Whilst under Boeck, approximately 40 per cent. of the patients were treated with potassium iodide and 3.6 per cent. with mercury in some form. Thus mercury cannot have had any influence on the outcome, and the author having dismissed the idea of potassium iodide having had any specific effect, leaves open the question of its having had any influence on the immune processes. In this connexion, however, it may be of interest to recall that Brown and Pearce (1923) saw in animals effects of potassium iodide that suggested a significant power of increasing the resistance to syphilis.

Patients were kept in hospital as long as they showed any sign of syphilis, the figures being: primary and secondary syphilis, males, 93.3 days ; females, 132.2 days ; secondary, males 64.3 days and females $104 \cdot 1$ days. Taking the figures for primary and secondary syphilis as a guide, the author thinks they indicate that the average duration of early syphilis when untreated is $\mathbf{4 . 6}$ months in females and 3.2 months in males. An objection to this estimate seems to lie in the fact that there is no information as to duration of the disease on first admission. Every syphilologist knows that the primary sore may still be present some months after its first appearance and when the patient is far advanced in the secondary stage. One would judge that the conditions favoured concealment since grape-vine intelligence would inform the district from which these patients came that admission to the syphilis wards in the Rikshospital would mean incarceration there for months and months. One can well imagine that, in such circumstances, application for admission would usually be regarded as a desperate last resort. Whatever may be one's judgment on such points, the longer duration of signs in females, on which the author comments; seems to be incontestable, especially when one can well imagine that the females were admitted long after the primary sore had developed and that in many cases the primary sore would be discovered for the first time after admission, a different case from that in males.

In his own words, the author aimed :

(1) To trace as many patients as possible to an " end point", defined as the last observation whether living or dead.

(2) To collect a maximum amount of clinical data (including data on treatment) on each patient from the date of his original discharge from Boeck's department, all through the interim period and up to the "end points".

(3) To determine the cause of death through study of post-mortem examinations, hospitalizations, death certificates, etc. with the maximum amount of accuracy.

(4) To examine at the Rikshospital as many living patients as possible and to employ as complete examinations as circumstances will permit, and to have examined elsewhere, according to the same principles, those patients who, for one reason or other, could not be brought to the Rikshospital.

In the next twelve pages are described the careful procedures to trace and identify the original patients. According to the author's Table 21, the number of living males at the time of the study was 72 of the original 446, and the number of females was 187 of the original 958 . Of these 259 living patients, 216 were personally examined during or shortly before the present investigation (1949-51) either at the Rikshospital or elsewhere, apparently by the author or under his direction (p. xlvi of Appendix). For the remainder of the 1,404 cases, living and dead, reliance had to be placed on records, the accuracy of which in respect of physical states may well have varied considerably. From his study of the steps described in this report, the reader must conclude that the utmost available information has been extracted from the records, and any limitations are certainly not due to any lack of diligence in those concerned in this inquiry.

In the results of the follow-up the patients were primarily classified as "Known", "Partially Known", and "Unknown". The "Known" were those who were alive at the time of the re-study (72 males and 187 females or about one-sixth of the basic material), and those who were dead but about whom there was sufficient information (259 males and 435 females). The "Partially Known" were those about whom one or more observations were available since discharge from Boeck's department, but about whom the end result was unknown (43 males and 151 females). The "Unknown" were those about whom no information was available since discharge from Boeck's department (72 males and 185 females). As far as could be ascertained, 83.4 per cent. of the study group had had no treatment, and of the remainder less than one half had had what could be regarded as adequate treat- 
ment since leaving Boeck's department. On this question of what may be regarded as having been adequate and what " highly inadequate " treatment, there may be room for difference of opinion-this point will be discussed later in connexion with cardiovascular syphilis-but here the author concludes that treatment subsequent to discharge from Boeck's wards " can only to a relatively small degree have interfered with the natural course of the infection in the present series ".

In an important chapter on secondary clinical relapse, the author discusses the views of different workers as to its aetiology, the chief schools being those who believe, like Meirowsky and Pinkus (1923), that syphilis pursues a rhythmic course, active manifestations alternating with latency, regardless of treatment, and those who believe that inadequate treatment provokes relapse. He quotes a number of sets of results obtained by different workers with varying amounts of arsphenamine-type remedies and heavy metal in the Salvarsan era and with penicillin after this. This is preliminary to the report of what occurred in the case of Boeck's patients. In this connexion, we are reminded of the great length of time the patients were in hospital after first admission. Of 335 males of all ages at time of first infection, 22.7 per cent. developed secondary relapse, and of 700 females, 24.0 per cent. Of 278 males aged 15 to 39 on first admission, 23.4 per cent. relapsed in this way, and of 612 females in this category, 24.3 per cent. Of the 244 who relapsed, 189 did so once only ; 46 , twice only ; eight, three times; and one, four times. In a comprehensive Table showing the sites of these secondary relapses, it is seen that 84.8 percent. were in the mouth and/or ano-rectal region. The importance of this from the point of view of spread of the infection is stressed by the author. In regard to the period which had elapsed between discharge from hospital and first relapse, it is shown that 88.2 per cent. occurred within the first year.

In an instructive discussion of these results, the author thinks they show that secondary clinical relapse cannot be regarded as a product of inadequate treatment and he adheres to the views of Meirowsky and Pinkus already mentioned.

After pointing out the difficulties of comparing the results in the Boeck series with those reported by other workers, a number of which the author quotes, he thinks that probably the nearest comparison is one with the two series quoted by Lomholt (1931) since these were studied in Denmark and, thanks to the fact that there all syphilitic serum tests are carried out in one institute, follow-up is probably more efficient than in any other country. This is the
Jersild system of nameless notification started in 1920 and sufficiently described in the report under review.

The first series quoted by Lomholt included 446 secondary cases treated in two hospitals in Copenhagen between 1910 and 1914 with two to three Salvarsan injections and thirty to fifty mercurial inunctions; $25 \cdot 1$ per cent. of them showed a clinical recurrence. In the second series, treated in the same hospitals between 1920 and 1927, with six to seven Salvarsan injections and more mercury or bismuth than in the first series, were 1,241 secondary cases and the clinical relapses traced in this group were $4 \cdot 1$ per cent. The author expresses doubt whether the results referred to by Lomholt can be accepted at their face value, especially those in the second series, having regard to the low relapse rate compared with that in other series "where considerably more adequate treatment has been employed". Here one wonders by what standard the author gauges the adequacy of the treatment given to the Danish cases. He quotes results reported by the American Cooperative Clinical Group and if the standard is that of the treatments shown in this series, one would, with respect, object that the two systems are not comparable as they were based on different principles. In the Danish system the arsenical remedies were given concurrently with the heavy metal, and in the American series, one gathers, the treatment was mostly on the Almkvist system of alternating continuous treatment, courses of arsphenamine alternating with courses of heavy metal. At the risk of starting a polemical discussion in this Journal, I would say that there is abundant evidence to show that the concurrent administration of both types of remedy is more efficient than giving them during different periods ; in other words $2+2$ on the concurrent system makes more than 4 and the same on the alternating continuous system makes less than 4 . At this stage one may perhaps be allowed to anticipate by saying that in respect of neuro-recurrences (expressed in the form of cranial nerve disturbances) the purely alternating continuous system has shown worse results in the American Cooperative Clinical Group series than befell the untreated Boeck cases. Another point in this argument of incomparability is the size of the individual dose. It is not enough to say that so many injections should be given ; what should be mentioned is the size of each dose and the intervals between doses. In regard to individual doses of the arsenical remedy, one would judge that, according to the principles of the late Prof. Rasch, those in the Danish cases were high. My own impression of clinical relapses after the course 
of treatment given to British soldiers in the war of 1914-18 makes me a little surprised that those in the second series quoted by Lomholt (1931) were as high as 4.1 per cent. Our "war course" was an imitation of that which had been reported as successful by Gennerich (1914), a naval surgeon working at Kiel-he had reported no clinical relapse within a period of at least a year in 92 primary and 81 secondary cases-and it seems to have been rather weaker than that described by Lomholt. I am sure that if our " war course " had been followed by even 1 per cent. of clinical relapses-and war conditions encourage reporting sick-I should soon have heard of it, considering the tens of thousands of early cases treated on this scheme every year of the war.

On the other hand, it seems rather a pity that the author of the work under review had not seen the results of treatment in a well-observed series of cases of early syphilis treated with mercury without any other aid than perhaps some potassium iodide. Such a series was reported by Gibbard and Harrison (1914) to the International Medical Congress which was held in London in 1913.

It may be of interest here as a sort of bridge between the untreated cases of Boeck and those treated with arsenicals and heavy metal, and also because the percentage of clinical relapses in this series was far higher than in the Boeck series. For the correctness of the figures given below I can vouch as I collected them. The aim of the collection was to see how much time was lost by a soldier under treatment by mercury, on a scheme drawn up by a War Office committee after careful inquiry into existing practice, as compared with that lost under treatment by Salvarsan and mercury as then practised. For the purpose the syphilis case records of men of the Brigade of Guards which had been returned to the War Office from 1906 to 1912 were scrutinized and the relapses in the first year of treatment were extracted, as well as the days spent in hospital, in all cases in which the treatment, (chiefly injections of mercurial cream) had been given with perfect regularity. The fact of relapse had been determined by the weekly medical inspection which all soldiers on the syphilis register had to undergo, and for any clinical relapse the soldier was admitted to hospital. In this way, 371 case records were examined and it was found that the percentage of cases that had relapsed at least once was 83.8 ( 315 cases). Of the toral, 151 had relapsed once only; 115 , twice ; and 49 , three or more times.

The reasons for this far higher incidence of clinical relapses in these soldiers treated with perfect regularity with mercury on what was then thought to be the best lines, than in the untreated cases of Boeck seem worth discussion. Were these well-fed and reasonably well-housed guardsmen, picked for their superior physique, naturally more prone to relapse than the down-and-outs who formed the material of the Oslo study? Or was the system of inspection practised in the British army more likely to discover relapses than the more or less voluntary civilian system, which depended on the patient seeking advice and treatment for some recurrence which in a good proportion of cases would not be very uncomfortable ? It seems to me quite possible that a patient who in the first instance had lain in hospital for several weeks under no treatment that would impress him as an active attack on his disease would not be very willing to return there, and, by wishful thinking, he might well persuade himself that the slight discomfort in his mouth was not due to any relapse of his syphilis or at any rate could be cured with a few bottles of some " blood mixture".

It might well be argued that the Boeck cases were longer in hospital in the first instance than were our guardsmen, who were there for an average of 6 weeks. It might further be argued that there were more primary cases in the soldiers. As to this I have no direct information, but the ratio of primary to secondary cases in the British Army at home in those days was approximately as 1 to 1 or about the same as in the Boeck series.

With all regard for the limitations of comparisons between results reported in different nations, one cannot escape the suspicion that, assuming the mercury neither provoked nor prevented clinical relapses, the guardsmen figures were nearer the truth in regard to the chances of secondary relapse than were the Oslo figures.

On page 137 , the author says that when primary syphilis is allowed to go untreated it "usually results in close to 100 per cent. secondary syphilis ". But he does not know how many primary cases never sought treatment and, on the other hand, anyone who has worked in a syphilis clinic for even a short time must have noted in the later cases quite a significant number who have no recollection of having seen any earlier manifestation of the disease. This is particularly noticeable in cases discovered by routine blood tests-in one series of 200 such cases taken seriatim, which I had questioned, more than half had no history whatever of anything which might in any way suggest syphilis-and it is notorious that in neurosyphilis and other late effects of this disease it is very common to find a blank history in this respect. 
The criticisms contained in the paragraphs above in no way mitigate my high opinion of the value of this study ; they are intended only to supplement it.

An interesting feature in the section dealing with secondary clinical relapse is that no significant difference was found between males and females in this respect, so that whatever factor may be responsible for the generally believed milder outcome in females, it does not operate in the earlier stages of the disease. It is possible, of course, that economic factors may have been to some extent responsible for a greater proportion of housekeepers than of breadwinners seeking treatment, with all its consequences in the shape of internment, loss of wages, and so forth.

The author comments on the fact of only one neuro-recurrence having been found in these secondary relapses. He says : "Neuro-recurrence may constitute a form of relapse that is practically always related to irregular or inadequate treatment". This does not say enough. It is well known that neuro-recurrence of the kind meant here, commonly expressed by paralysis of one or more cranial nerves, became a prominent feature in the early days of the Salvarsan era, and it has been proved beyond any reasonable doubt that the cause of the increase was arsphenamine treatment, using relatively high doses, without concomitant heavy metal. Neuro-recurrence, in fact, is a form of relapse commonly related to inadequate treatment of $a$ certain kind.

After, rightly, emphasizing the caution which must be exercised in comparing the results shown in this study with those in treated syphilis, the author says : "As far as the comparisons go, indication is that even inadequate treatment protects against clinical secondary relapse". The results in cases treated solely, but with perfect regularity, with mercury which have been cited above suggest that this is applicable only to a combined arsphenamine and heavy metal treatment or to one employing one or more reliable antibiotics, with or perhaps without heavy metal.

In his chapter on "Benign Tertiary Syphilis", which includes gummata of the skin and mucous membranes and skeletal structures, the author reviews the literature, and one is struck by the diversity of experience in respect of incidence and of views on the question whether such outbreaks protect against more serious manifestations in the cardiovascular and/or the central nervous system.

In regard to causes of benign tertiary syphilis the author speaks of " upset in the parasite-host relationship resulting from re-activation of re- maining treponemes in a sensitized host ", bur not a word, as far as I have been able to see, is said about the factor of trauma. It is difficult to believe that a syphilologist could practise his specialty for long before being impressed by the overwhelming importance of trauma in the precipitation of tertiary, or even secondary, relapse. This is transferring the weight to the other pan of the scale.

The difficulty of comparing the results in the Boeck cases with those reported by others, some qucted, is again emphasized. For the series under study the author used the "Known" and the “Partly Known", viz. 374 males and 773 females, as denominator. Of this number the author found that 15.8 per cent. developed some form of benign tertiary syphilis; he gives reasons for supposing the percentage to be a minimum. He does not, however, seem to think many of the Boeck cases who had remained in Oslo escaped registration by seeing private practitioners because that would be too expensive for most of the patients comprising the Boeck series. He does not mention the possibility of self-treatment by blood mixtures (which may contain potassium iodide) or even such homely remedies as poultices (which $I$ have known used with good effect), as an alternative to reporting to the Indigents' authorities and possible internment. The fear of being infectious, or of being considered infectious, remains with a high proportion of syphilitics throughout life.

The views of Grin (1953) that in areas of endemic syphilis "super-infection plays a major role in the development of benign tertiary syphilis" are discussed and the author seems inclined to agree. If the relatively small doses of infectious material which must be concerned in contamination of one person by another in an endemic area are sufficient to provoke tertiary lesions, one wonders why Finger and Landsteiner (1906) had to use such large amounts of live syphilitic material, inserted moreover into pockets under the epidermis, to produce tertiary-like lesions.

The chapter on neurosyphilis, which occupies 68 pages, is a very valuable addition to the literature on the subject but cannot with justice be summarized here.

In the 953 "Known" cases in the study group considered by sexes the author found the following percentages of the respective forms of neurosyphilis : meningo-vascular plus vascular, males, 3.3, females, 1.7 ; general paresis, 3.0 and 1.7 ; tabes, 2.6 and 1.5 ; gumma of brain, 0.3 and 0.2 .

The author compares the figures in his study series with those found by Nielsen (1950), who had 
followed up 467 male patients who during the period 1913-20 had received two to three injections of Salvarsan and fifty inunctions of mercury. The cases had been followed for 29 to 36 years and the percentages were : general paresis, 4.3 ; meningovascular, $3 \cdot 2$ : tabes, $1 \cdot 1$. In addition there were seven with eye manifestations and one with an ear ailment.

Comparing his results in the Boeck series with those found by Bruusgaard in the same material, the author found a gross similarity but in respect of sex and type of neurosyphilis such dissimilarities as made the two not comparable, though both were derived from Boeck's cases. That should make one think !

In cardiovascular syphilis, which occupies 75 pages, the author follows much the same lines as in other sections, giving a critical review of the more important papers on the subject as a preliminary to the results of his own investigation. In the review the author discusses the reliability of the diagnosis of " uncomplicated aortitis" made ante mortem and seems sceptical. In regard to complicated aortitis, under which he lists aneurysm, ostial stenosis, and aortic regurgitation, he agrees that the difficulties are less, but I could not find any discussion of the diagnosis of aortic incompetence caused by syphilis from that due to other causes such as rheumatism and atheroma. This seems to be an important defect since the diagnosis seems to have been made chiefly by clinical examination ante mortem of a material derived from a class whose social circumstances would make its individuals more prone than the average to contract acute rheumatism. He discusses the reasons for the greater proportional incidence of cardiovascular syphilis in males than in females, with apparently an open verdict. The author again emphasizes the difficulty of comparing the results in one series with those in another, particularly when an author groups all cardiovascular syphilis together and includes in it uncomplicated aortitis diagnosed ante mortem. Later in this review I shall hope to show the fallacy of grouping together all cardiovascular syphilis with the inclusion of aortic regurgitation.

He, rightly I think, devotes much attention to the Nielsen series, already mentioned, because of the superiority of the follow-up that is possible in Denmark thanks to the Jersild system. He describes the treatment given in the first instance as " highly inadequate ", but reference to the paper by Nielsen shows that it comprised 1 to $3 \mathrm{~g}$. old Salvarsan plus fifty inunctions of mercury, which would make the treatment spread over about 8 weeks, ending, I should guess, with a good dose of " 606 ". For reasons already given, whatever its defects in preventing late neurosyphilis, I should describe this course as " nearly adequate", the elimination of the last small vestiges of infection in remote corners of the body requiring far more treatment than suffices to prevent cardiovascular syphilis. In regard to Nielsen's cases the author poses the following questions :

(1) Can it be assumed with reasonable certainty that all or the majority of the patients who developed symptoms and signs of aortic insufficiency or aneurysm have at one time or another sought medical advice and thus submitted themselves to examination?

(2) If examined, what proportion was hospitalized and where, and what proportion was seen by practitioners?

(3) To what extent were serologic tests for syphilis employed by the hospitals and the practitioners respectively during the period of time through which the patients in question lived?

(4) How many patients died of other causes with these syphilitic complications undiagnosed?

(5) If any of these patients came to autopsy, were the findings of syphilis recorded also?

For reasons given, Gjestland thinks the results in the Nielsen series must be regarded as a minimum. Nielsen found a total of 3.6 per cent. cardiovascular syphilis, including 2.8 per cent. uncomplicated aortic aortitis and only 0.8 per cent. aortic insufficiency and aneurysm. The author seems surprised by the lowness of these figures, but I think I can lend some support to the Danish results from another angle. The evidence is not so precise as it is given in a follow-up study, such as the one under review, but it is worth consideration if only to show what a treatment not much, if any, more strenuous than that given to the Danish cases must have done to prevent cardiovascular syphilis in British males who contracted syphilis during the war of 1914-18.

A number of years ago, when preparing a paper on the prognosis of syphilis for the Assurance Medical Society (Harrison, 1940), I thought it would be interesting to see if the great increase in syphiliswhich we know, without having any precise figures to prove its degree, must have occurred in our nationals during the war of 1914-18 and immediately after-would be reflected in an increase of mortality from those late effects of syphilis on which treatment after their detection did not seem to have had any striking effect. For this reason I excluded neurosyphilis and concentrated on aneurysm and aortic incompetence. The Table shows deaths and crude death rates in England and Wales from aneurysm (1911-39) and from aortic valve disease (1921-39). 
TABLE

ANEURYSM AND AORTIC VALVE DISEASE IN ENGLAND AND WALES

Annual Deaths and Crude Death Rates per Million Living

\begin{tabular}{|c|c|c|c|c|c|c|c|c|}
\hline \multirow{3}{*}{ Year } & \multicolumn{4}{|c|}{ Aneurysm } & \multicolumn{4}{|c|}{ Aortic Valve Disease } \\
\hline & \multicolumn{2}{|c|}{ Males } & \multicolumn{2}{|c|}{ Females } & \multicolumn{2}{|c|}{ Males } & \multicolumn{2}{|c|}{ Females } \\
\hline & No. & Rate & No. & Rate & No. & Rate & No. & Rate \\
\hline $\begin{array}{l}1911 \\
1914 \\
1917 \\
1921 \\
1926 \\
1931 \\
1934 \\
1935 \\
1936 \\
1937 \\
1938 \\
1939\end{array}$ & $\begin{array}{r}935 \\
902 \\
770 \\
787 \\
777 \\
989 \\
984 \\
982 \\
1,030 \\
1,001 \\
1,024 \\
1,010\end{array}$ & $\begin{array}{l}53 \\
50 \\
51 \\
44 \\
42 \\
52 \\
51 \\
50 \\
53 \\
51 \\
52 \\
51\end{array}$ & $\begin{array}{l}225 \\
229 \\
225 \\
205 \\
245 \\
325 \\
431 \\
459 \\
490 \\
528 \\
551 \\
554\end{array}$ & $\begin{array}{l}12 \\
12 \\
11 \\
10 \\
12 \\
16 \\
20 \\
22 \\
23 \\
25 \\
26 \\
26\end{array}$ & $\begin{array}{l}1,917 \\
2,076 \\
2,359 \\
2,118 \\
2,144 \\
2,051 \\
1,919 \\
1,789 \\
1,822\end{array}$ & $\begin{array}{l}\text { Not } \\
106 \\
111 \\
123 \\
109 \\
110 \\
105 \\
97 \\
90 \\
93\end{array}$ & $\begin{array}{r}\text { vailable } \\
\\
850 \\
956 \\
1,167 \\
1,044 \\
1,048 \\
1,014 \\
969 \\
892 \\
916\end{array}$ & $\begin{array}{l}43 \\
47 \\
56 \\
50 \\
50 \\
48 \\
45 \\
42 \\
42\end{array}$ \\
\hline
\end{tabular}

The Table shows that, whereas from 1914 to 1939 there was no significant increase in mortality of males from aneurysm, that of females had more than doubled, the increase having started in 1931. The explanation offered is that syphilis increased greatly in females as well as in males during the war of 1914-18, but that whereas males, being mostly in the fighting services, were treated, females, the civilian V.D. Service being then in its infancy, were mostly untreated. On the other hand, the figures relating to aortic valve disease show no such change as those relating to aneurysm, and I suggest that the syphilitic element in them is buried in the numbers of deaths from aortic valve disease due to other causes. It may be argued that the figures have been taken too early after the probable dates of infection and I have studied the figures after 1939 with this objection in mind. They are not very easy to follow owing to changes in classification of the different causes of death and it would burden this commentary too much to explain them here, but they certainly do not show any increase in mortality from either aneurysm or aortic incompetence after 1939.

In the patients of the Boeck series aged less than 15 years at the time of infection, no case of cardiovascular syphilis was later discovered; this was in contrast to a finding of 12.3 per cent. in the 73 whose syphilitic infection was discovered at ages over 40 years and of 10.4 per cent. in all over 15 years at the time of first infection. The greater incidence of cardiovascular disease in syphilitic males is illustrated by the overall percentage of $\mathbf{1 3 . 6}$ as compared with $7 \cdot 6$.

In all this one may justifiably wonder how much cardiovascular syphilis was missed by the observers of these cases, whether clinically or in the postmortem room, and when, on the other hand, one thinks of the fallacy of including all aortic incompetence under the heading of cardiovascular syphilis, there does seem to be room for some scepticism as to the prognostic value of these figures.

In the Boeck cases aged over 15 years at infection, the duration of the disease at the time of recognition of the cardiovascular complication was 30.1 years in males and 29.8 in females. As another example of the difficulty of comparing series in different countries with each other, Gjestland quotes the findings of Frazier and $\mathrm{Li}$ (1948) in white patients at the Johns Hopkins Hospital. Their figures were 18.1 years for males and $14 \cdot 1$ years for females, and these were arrived at by deducting from the mean ages of the cardiovascular patients under their study the mean ages of the males and females arriving at their clinic with fresh infections at the time of their study. These mean ages were 30 and 26 years respectively and the author quotes the following comment by Frazier and $\mathrm{Li}$ : "... for, contrary to the commonly held opinion, syphilis is not a disease of youth but rather one of sexual maturity ". In this connexion it may be of interest to quote here the ages at first infection of the cases whose records, collected from five nations, were analysed for the Expert Committee of the League of Nations by Prof. H. Martenstein (1935) from approximately the end of 1929 to 1935 . The sexes were not differentiated and the ages were given in 5-year periods, which showed for every nation an outstanding preponderance of infections in the 21-25 year age group. The mean ages by nations were : Denmark, 2,308 cases, $24 \cdot 8$ years ; Germany, 2,873 cases, $25 \cdot 1$ years ; Great Britain, 3,123 cases, $27 \cdot 7$ years ; United States, 3,741 cases, 26.1 years. Thus the mean age of the American cases did not differ materially from that found in the Boeck cases.

The author stresses the far higher proportion of males than of females with cardiovascular syphilis who died of it, 61.0 per cent. as compared with 47.6. He shows that there is no point on which the results of this re-study can be compared with those of Bruusgaard in respect of cardiovascular syphilis. In the next chapter the author discusses the prognostic import of secondary relapses. He found no significant difference, in respect of late effects, between those who had suffered secondary relapse and those who had not. He could find no evidence, in these cases, that benign tertiary syphilis protected against more serious forms.

The causes of the excess mortality, apart from that due to syphilis, which afflicts syphilitics are always interesting, and the author, as a preliminary to his report on what happened in this respect to Boeck's cases, quotes the two conflicting views, thus :

(1) Syphilis is a disease that practically always is associated with socio-economic status, or rather with 
various disturbances of the socio-economic equilibrium. Therefore, whenever we choose a relauvely large population-group of syphilitics for study, we invariably end up with patients who by and large come from the lower socio-economic strata of society. These same patients, in addition to the risk imposed on them by the syphilitic infection per se, are naturally also exposed to the risk of a whole series of other diseases more commonly encountered in such population-groups, and naturally they would be expected to show a greater mortality from all causes than nonsyphilitics do. Syphilis, therefore, can only be partly responsible for the excess mortality usually found.

(2) Syphilis is a generalized systemic disease affecting to a variable degree most of the organ-systems of the body, True enough, in a certain proportion of those infected the disease causes death primarily, but it may also, withcut causing death directly, produce changes in the host, presumably non-specific in character, that increase the morbidity and thereby the mortality from many illnesses other than syphilis.

The author thinks that the Alabama study in which the syphilitics showed a greater mortality from other diseases than did the controls lends support to the second of these views. He also quotes the experiments of Rosahn (1952) on mice, which showed that "syphilitic infection in mice, even though it produces no lesions of syphilis, in and of itself causes a reduction in longevity".

In regard to the Boeck cases, a study of the mortality in Oslo by regions showed that in the region providing these cases the "average excess mortality in East Oslo (all ages) ranged between 16 and 27 per cent. in males and between 25 and 38 per cent. in females". The excess mortality in the Boeck cases as compared with that in the region from which they came was 53 per cent. in males and 63 per cent. in females (all ages). In the discussion following the relating of these facts, the author finally inclines to the view that the excess mortality was due to the socio-economic status of the syphilitics of East Oslo being lower than that of the non-syphilitics of the same region (low though this might be). Finally, he agrees with Schamberg (1945), who said that syphilis kills only through the lethal effects of its serious late manifestations.

There we must leave it to the reader, but one cannot escape the strong suspicion that much syphilis in this Boeck material must inevitably have escaped the notice of the scrutineers. Apart from the fact that an important part of the evidence is documentary with reliance on reports by persons who might not be very syphilis-conscious, without microscopic examination autopsy evidence may lack information respecting those insidious round-celled infiltrates on which Warthin (1914-29) reported so fully and which may bedevil the functions of important organs.
On the question of spontaneous cure, about which so much nonsense has been written on the basis of Bruusgaard's figures, nonsense for which Bruusgaard was in no way responsible, the author concludes that the Bruusgaard figures afford no answer and he thinks that the re-examination under review has not brought us any nearer to it.

The grand conclusion is that "somewhere between sixty and seventy, and probably closer to sixty than seventy, out of every one hundred untreated syphilitics went through life with little or no inconvenience as a result of the disease".

The cynical student might ask what value that knowledge may be in the clinic or the consulting room, seeing that nobody in his senses is to-day going to repeat Caesar Boeck's experiment. But that does not detract from the value of this study; apart from the great mass of information which the author has gathered so skilfully into this monograph, it is a model which every venereologist should have before him when he is tempted to play with figures relating to results of infection or of treatment, or when he reads some other person's efforts in that direction.

\section{REFERENCES}

Brown, W. H., and Pearce, L. (1923). Proc. Soc. exp. Biol. (N. Y.), 20, 476.

Bruusgaard, E. (1929). Arch. Derm. Syph. (Wien), 157, 309.

Deibert, A. V., and Bruyère, M. C. (1946). Vener. Dis. Inform., $27,301$.

Finger, E., and Landsteiner, K. (1906). S.B. Akad. Wiss. Wien, Abt. 3, 115, 179

Frazier, C. N., and Li, Hung Chiung (1948). " Racial Variations in Immunity to Syphilis." Univ. Chicago Press.

Gennerich, - . (1914). Münch. med. Wschr., 61, 513.

Gibbard, T. W., and Harrison, L. W. (1914). J. roy. Army med. Cps, 22, 247.

Gjestland, T. (1955). “The Oslo Study of Untreated Syphilis", Acta derm.-venereol. (Stockh.), 35, Suppl. 34.

Grin, E. (1953). " Epidemiology and Control of Endemic Syphilis. Report of a Mass Campaign in Bosnia." W.H.O. Monograph Series, No. 11. W.H.O., Geneva.

Harrison, L. W. (1932). Bull. Hyg. (Lond.), 7, 223.

- (1939). Ibid., 14, 482.

(1940). British Journal of Venereal Diseases, 16, 1.

(1941). Bull. Hyg. (Lond.), 16, 458.

Heller, J. R., and Bruyere, P. T. (1946). Vener. Dis. Inform., 27, 34. Lomholt, E. (1931). Hospitalstid., 74, 1175.

Martenstein, H. (1935). Quart. Bull. Hlth Org. L.o.N., 4, 129

Meirowsky, E., and Pinkus, F. (1923). “Die Syphilis." Springer, Berlin.

Nielsen, J. P. (1950). Acta derm.-venereol. (Stockh.), 30, 507.

Pesare, P. J., Bauer, T. J., and Gleeson, G. A. (1950). Amer. J. Syph., 34, 201.

Rosahn, P. D. (1937). Amer. J. med. Sci., 193, 534.

(1952). Arch. Derm. Syph. (Chicago), 66, 547.

Schamberg, I. L. (1945). Amer. J. Syph., 29, 529.

Sowder, W. T. (1940). Ibid. 24, 684.

Vonderlehr, R. A., Clark, T., Wenger, O. C., and Heller, J. R. (1936). Vener. Dis. Inform. 17, 260

Warthin, A. S. (1914). Amer. J. med. Sci., 147, 667.

- (1916). J. infect. Dis., 19, 138.

(1918). Amer. J. Syph., 2, 425.

(1922). J. infect. Dis., 30, 569.

(1926). Amer. J. Syph., 10, 1.

(1928). Ibid., 12, 301 .

(1929). Brit. med. J., 2, 236. 